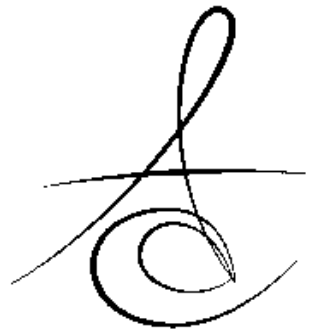

\title{
DÖRT KÖKLÜ ALT İKİNCİ BÜYÜK AZI DİŞİNİN KONİK IŞINLI BİLGİSAYARLI TOMOGRAFİ İLE DEĞERLENDİRİLMESİ VE ENDODONTİK TEDAVİSİ: OLGU SUNUMU
}

\section{CONE BEAM COMPUTED TOMOGRAPHY EVALUATION AND ENDODONTIC TREATMENT OF MANDIBULAR SECOND MOLAR WITH FOUR ROOTS: A CASE REPORT}

\author{
Dt. Hicran ATEŞ GÜNDÜZ* \\ Dt. Damla ÖZsU* \\ Yrd. Doç. Dr. Ertuğrul KARATAŞ * \\ Doç. Dr. K. Meltem ÇOLAK TOPCU* \\ Dt. İ. Şevki BAYRAKDAR**
}

Makale Kodu/Article code: 1683

Makale Gönderilme tarihi: 07.05.2013

Kabul Tarihi: 29.09.2014

\section{ÖZET}

Kök kanal anatomisi ile ilgili yeterli bilgiye sahip olmak kök kanal tedavisinin başarısını arttırmaktadır. Alt ikinci büyük azı dişlerinde kök kanal anatomisiyle ilgili birçok konfigürasyon gözlense de bu dişler çoğunlukla 2 köklü ve 3 kanalıdır. Bu raporda 4 köklü 4 kanallı bir alt ikinci büyük azı dişinin kök kanal tedavisi 3 boyutlu görüntüleme tekniklerinden konik ışınlı bilgisayarlı tomografi yardımı ile sunulmuştur.

Anahtar kelimeler: Alt ikinci büyük azı, konik ışınlı bilgisayarlı tomografi

\section{GİRIŞ}

Endodontik tedavinin başarısı, kök kanal sisteminin etkin bir biçimde temizlenmesi, şekillendirilmesi ve sızdırmaz bir şekilde doldurulmasına bağlıdır. Bu yüzden hekimin kök kanal anatomisi ve morfolojisini eksiksiz bilmesi uygulayacağı tedavinin başarısı için gereklidir. ${ }^{1}$ Diğer taraftan tanı amacıyla çekilen radyografiler de hekime kök kanal anatomisini ve olabilecek varyasyonları anlayabilmesinde yardımcıdır. ${ }^{2,3}$

Genellikle alt ikinci büyük azı dişleri 2 köklü ve 3 kanalıdır. Köklerden biri mezialde biri distaldedir. Mezialde iki kanal distalde ise bir kanal mevcuttur. ${ }^{4} 5$ Fakat bu dişlerde farklı birçok morfoloji de görülebillir. C şekilli kök kanal kanal yapısı olabileceği gibi ekstra kök ve kanallara da rastlanabilinir. ${ }^{5,6}$

\section{ABSTRACT}

Due to having thorough knowledge on the root canal anatomy and the variations will increase the success of the root canal treatment. Although its most common configuration of the mandibular second molars is having two roots and three root canals. This report presents the endodontıc treatment of a four rooted mandibular second molar, diagnosed with the assistance of cone beam computed tomography .

Key words: Mandibular second molar, cone beam computed tomography

Kök kanal sistemindeki varyasyonların daha iyi anlaşılabilmesi için ise geleneksel radyografiler hekime yardımcı olurken 2 boyutlu görüntü oluşturmaları sebebiyle bazı durumlarda yetersiz kalabilirler. Bu yüzden günümüzde 3 boyutlu görüntü oluşturabilen konik ışınlı bilgisayarlı tomografilerin(KIBT) kullanımı özellikle dişlerin morfolojik analizlerinde doğru değerlendirmeler yapabilmek için yaygınlaşmıştır. ${ }^{7,8}$

$\mathrm{Bu}$ olgu bildiriminde çok sık rastlanmayan dört köklü dört kanallı alt ikinci büyük azı dişinin konik ışınlı bilgisayarlı tomografi ile değerlendirilmesi ve kök kanal tedavisi anlatılmaktadır.

\section{OLGU SUNUMU}

42 yaşındaki erkek hasta sağ alt çene bölgesindeki ağrı şikayeti nedeniyle Atatürk Üniversitesi Dişhekimliği Fakültesi Endodonti Kliniği'ne başvurdu. Hastadan alınan anamnezde sağ alt ikinci büyük azı

\footnotetext{
* Atatürk Üniversitesi Diş Hekimliği Fakültesi Endodonti Anabilim Dalı

${ }^{* * *}$ Atatürk Üniversitesi Diş Hekimliği Fakültesi Ağız Diş Çene Radyolojisi Anabilim Dalı
} 
dişinde son 4 gündür spontan ağrılar olduğu ve bu ağrıarın çok şiddetli olduğu öğrenildi. Yapılan ağız içi muayenesinde sağ alt ikinci büyük azı dişinde perküsyona hassasiyet ve MO kavite formunda çürük tespit edildi. Radyolojik tetkikte ise çürüğün pulpaya kadar uzandığı fakat periapikal bölgede herhangi bir lezyon olmadığı görüldü.(Resim:1) Ayrıca mezial kökün olması gerektiğinden kalın ve fazla radyo opak olduğu görüldü ve bu durum da mezialde ekstra kök olabileceğini düşündürdü. Hastadan alınan anamnezde hastanın herhangi bir sistemik problemi olmadığı öğrenildikten sonra hastaya lokal anestezi enjekte edildi. Lastik örtü ile dişin izolasyonu sağlandıktan sonra çürük dokular uzaklaştıııldı ve giriş kavitesi açıldı. Başlangıçta biri distalde ikisi mezialde 3 kanal tespit edildi. Ayrıntılı incelemeden sonra ise mezialde bir tane daha kanal görüldü.(Resim:7) Kök kanal morfolojisinin daha iyi anlaşılabilmesi için dişten konik ışınlı bilgisayarlı tomografi (KIBT) ile görüntü alınmasına karar verildi. Alınan tomografi görüntülerinde mezialde 3 kökün olduğu tespit edildi.(Resim:5,6,8) Kavite tekrar açıldığında kanallar ekstirpe edildi ve çalışma boyunu belirlemek için apex locater ile ölçüm yapıldı. Daha sonra bu çalışma boylarını doğrulamak amacıyla ağız içi röntgen çekildi.(Resim:2) Kanalların çalışma boyları tespit edildikten sonra kök kanalları ProTaper Universal (Dentsply, Maillefer) döner alet sistemi ile şekillendirildi ve \%5.25 lik sodyum hipoklorit solüsyonu ile irrige edildi. Kanallara kalsiyum hidroksit pastası yerleştirdikten sonra pulpa odasına küçük bir pamuk parçası koyuldu ve kavite geçici dolgu maddesiyle kapatıld. Hasta bir hafta sonraki randevusuna geldiğinde hiçbir şikayeti yoktu. Geçici dolgu kaldırılıktan sonra kanallar \%5.25 lik NaOCl ile kök kanallarının irrigasyonu yapıldı ve kanallar kağıt konilerle kurulandı. Kök kanalları lateral kondensasyon yöntemi kullanılarak AH plus (Dentsply De Trey GmbH, Konstanz, Germany) kanal patı ve güta perka (Resim 2) ile dolduruldu. Dişin üst restorasyonu kompozit kullanarak bitirildi.(Resim:4)

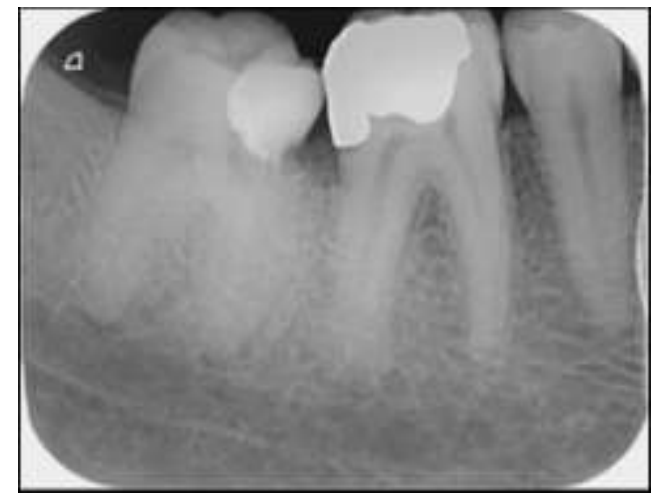

Resim 1 .

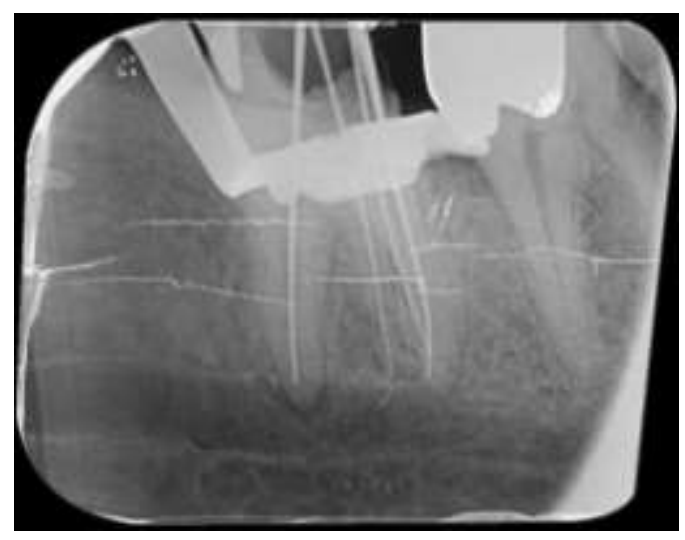

Resim 2.

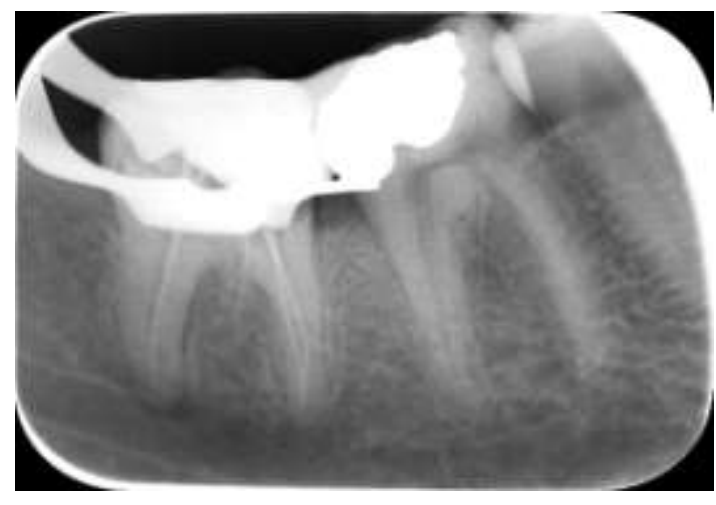

Resim 3 . 


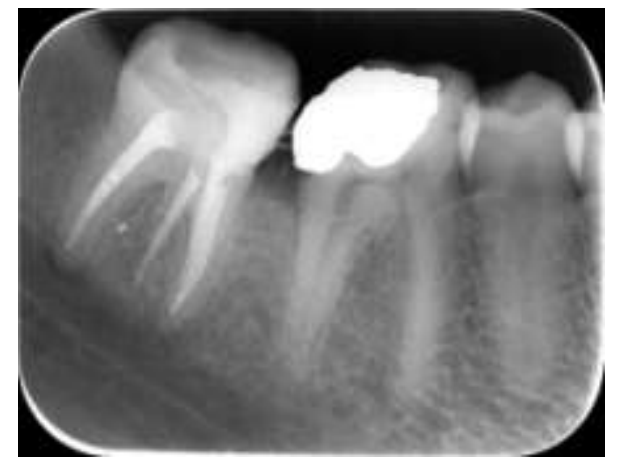

Resim 4 .

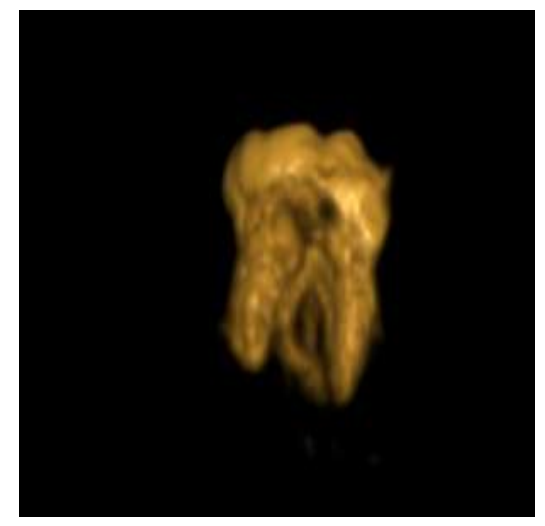

Resim 5.

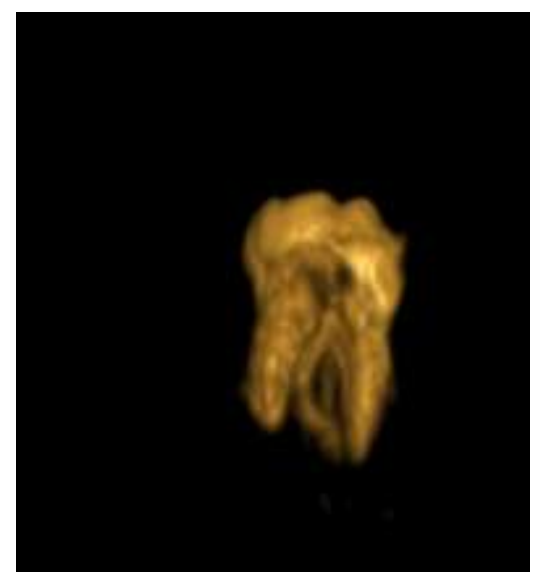

Resim 6.

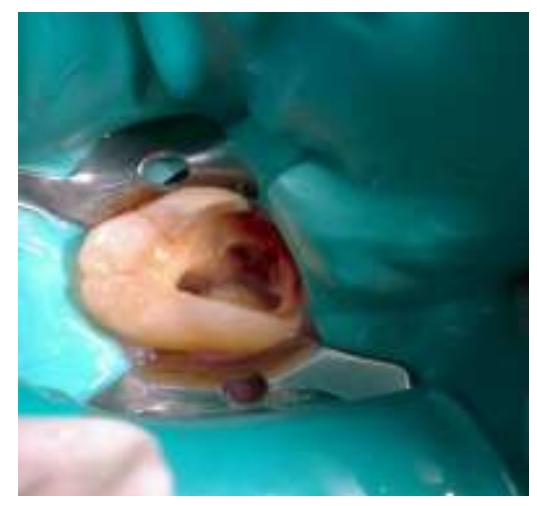

Resim 7.

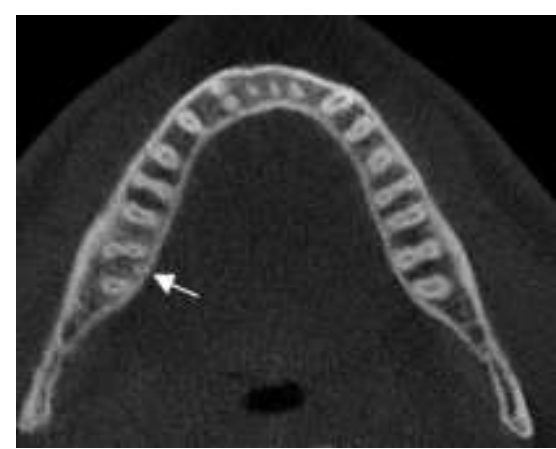

Resim 8.

\section{TARTIŞMA}

Kök kanallarının anatomisi ve morfolojisi hakkında eksiksiz bilgi sahibi olmak hekimin yapacağı tedavinin başarılı olmasında doğrudan etkilidir. Hekim dişlerde olabilecek anatomik varyasyonlarla ilgili de dikkatli olmalı ve mutlaka görüntüleme tekniklerinden de tedaviye başlamadan önce ve tedavi sırasında yararlanmalıdır.

Geleneksel ağız içi radyografiler kök kanal anatomisini değerlendirmede rutin olarak kullanılır fakat karmaşık kök kanal anatomisini değerlendirmede yeterli olamayabilirler. Çünkü geleneksel radyografilerle 2 boyutlu oluşan görüntüler 3 boyutlu anatominin net bir şekilde anlaşılmasını zorlaştırır. ${ }^{9}$

1990 yılından itibaren bilgisayarlı tomografinin endodontide kullanılmaya başlanmasıyla son yıllarda popülerliği diş hekimleri için artmıştır. KIBT herhangi bir cerrahi müdahaleye gerek kalmadan dişlerden farklı eksenlerde kesitler alınmasını sağlayarak karmaşık anatomili dişlerden daha net görüntü alınmasını sağlar. Neelekantan ve arkadaşları yaptıkları bir çalışma sonu-

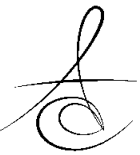


cunda kök kanal morfolojisini değerlendirmede bir çok yöntem içerisinde KIBT yi en iyi görüntüleme yöntemi olarak rapor etmişlerdir. ${ }^{10}$ Matherne ve arkadaşları gerçekleştirdikleri çalışmada ise çekilmiş dişlerden periapikal teknik kullanarak periapikal radyografiler almışlar ve bunlar KIBT ile alınan görüntülerle karşılaştırımışır. Periapikal radyografilerle yapılan değerlendirmede $\% 40$ oranında en az bir kanalın tespit edilemediği bildirilmiştir. ${ }^{11}$ Yine endodontik tedaviyi gerçekleştirirken mevcut kök kanal sisteminde olduğunu düşündüğümüz kanal sayısından daha fazla kanal aranması gereklilik olmuştur. Coton ve arkadaşlarının bildirdiği bir olguda kanal tedavisi bittiği halde ağrı şikayetinin geçmediği bir hastada geleneksel radyografilerle alınan görüntülerde herhangi bir patoloji görülmez iken KIBT ile yapılan değerlendirmede doldurulmamış fazla bir kanal tespit edilmiştir. ${ }^{12}$ Bu vaka raporunda da başlangıçta geleneksel ağız içi radyografi tekniği ile net bir şekilde gözlemleyemediğimiz ekstra kök ve kanal varlığını, KIBT ile alınan görüntüler ve kesitler ile net bir şekilde gözlemleyerek tedavimizi bitirdik ve $\mathrm{KIBT}^{\prime}$ nin bu tip vakalardaki görüntüleme avantajını da görmüş olduk.

Morfolojik olarak, alt ikinci büyük azı dişleri alt birinci büyük azı dişlerine benzerdir fakat kökleri daha kısa ve eğimlidir. Diğer taraftan bu dişlerde anatomik varyasyonlar daha çok gözlenir. ${ }^{13}$ Yapılan birçok çalışmada alt büyük azı dişleriyle ilgili varyasyonlar rapor edilmiştir. ${ }^{14-17}$ Manning çekilmiş alt ikinci büyük azı dişleriyle yaptığı çalışmada \%22 oranında tek kök, $\% 76$ oranında iki kök, \%2 oranında 3 kök bulmuştur. ${ }^{18}$ Costa Rocha ise 628 adet çekilmiş alt ikinci ve birinci büyük azı dişlerinin anatomileriyle ilgili çalışma yapmıştır. Çalışmanın sonuçları dişlerin \%84.1 oranında 2 ayrı köklü, \%15.9 oranında kaynaşmış köklü ve $\% 1.5$ oranında 3 köklü olduklarını göstermiştir. ${ }^{19}$ Türk popülasyonu içerisinde yapılan çalışmada ise alt ikinci büyük azı dişlerinin $\% 85.4$ oranında 2 köklü , $\% 8.97$ oranında tek köklü ve \%3.45 oranında 3 köklü olduğu tespit edilmiştir. Yine aynı çalışmada alt ikinci büyük azı dişlerinin \%72.8 3 kanallı, \%22.8 2 kanallı, \% 2.27 4 kanallı ve $\% 2.05$ oranında tek kanallı olduğu gösterilmiş ve mezialde veya distalde 3 kanalı olan hiçbir diş tespit edilememiştir. ${ }^{20}$

Sonuç olarak bu olgu raporunda çok nadir karşılaşılan karmaşık bir morfolojiye sahip alt ikinci büyük azı dişinin kök kanal tedavisinden geleneksel radyografiler ve konik ışınlı bilgisayarlı tomografi ile alınan görüntüleri ile kapsamlı bir şekilde bahsettik. Klinikte karşımıza çıkabilecek bu tür anatomik farklılıklara iyi bir klinik değerlendirme ve farklı görüntüleme tekniklerini kullanarak yaklaşırsak daha başarı kök kanal tedavileri yapılabileceği görülmektedir.

\section{KAYNAKLAR}

1. Baratto-Filho F, Fariniuk LF, Ferreira EL, Pecora JD, Cruz-Filho AM, Sousa-Neto MD. Clinical and macroscopic study of maxillary molars with two palatal roots. Int Endod J 2002, 35: 796-801.

2. Segura-Egea JJ Jimenez-Pinzon A, Rios-Santos JV. Endodontic therapy in a 3-rooted mandibular first molar: importance of a thorough radiographic examination. J Can Dent Assoc 2002, 68: 541-4.

3. Reeh ES. Seven canals in a lower first molar. J Endod 1998, 24: 497-9.

4. Min Y, Fan B, Cheung GS, Gutmann JL, Fan M. Cshaped canal system in mandibular second molars Part III: The morphology of the pulp chamber floor. J Endod 2006, 32: 1155-9.

5. Gulabivala K, Aung TH, Alavi A, Ng YL. Root and canal morphology of Burmese mandibular molars. Int Endod J 2001, 34: 359-70.

6. Ahmed HA, Abu-bakr NH, Yahia NA, Ibrahim YE. Root and canal morphology of permanent mandibular molars in a Sudanese population. Int Endod J 2007, 40: 766-71.

7. Neelakantan $P$, Subbarao C, Ahuja R, Subbarao CV, Gutmann JL. Cone-beam computed tomography study of root and canal morphology of maxillary first and second molars in an Indian population. J Endod 2010, 36: 1622-7.

8. Wang $Y$, Zheng $\mathrm{QH}$, Zhou XD, Tang L, Wang Q, Zheng GN, Huang DM. Evaluation of the root and canal morphology of mandibular first permanent molars in a western Chinese population by conebeam computed tomography. J Endod 2010, 36: 1786-9.

9. Patel S, Dawood A, Whaites E, Pitt Ford T. New dimensions in endodontic imaging: part 1. Conventional and alternative radiographic systems. Int Endod J 2009, 42: 447-62.

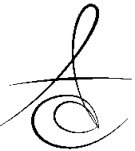


10. Neelakantan P, Subbarao C, Subbarao CV, Ravindranath $M$. Root and canal morphology of mandibular second molars in an Indian population. J Endod 2010, 36: 1319-22.

11. Matherne RP, Angelopoulos C, Kulild JC, Tira D. Use of cone-beam computed tomography to identify root canal systems in vitro. J Endod 2008, 34: 87-9.

12. Cotton TP, Geisler TM, Holden DT, Schwartz SA, Schindler WG. Endodontic applications of conebeam volumetric tomography. J Endod 2007, 33: 1121-32.

13. Vertucci FJ. Root canal anatomy of the human permanent teeth. Oral Surg Oral Med Oral Pathol 1984, 58: 589-99.

14. Carlsen O. Root complex and root canal system: a correlation analysis using one-rooted mandibular second molars. Scand J Dent Res 1990, 98: 27385.

15. Bond JL, Hartwell GR, Donnelly JC, Portell FR. Clinical management of middle mesial root canals in mandibular molars. J Endod 1988, 14: 312-4.

16. Weine FS, Pasiewicz RA, Rice RT. Canal configuration of the mandibular second molar using a clinically oriented in vitro method. J Endod 1988, 14: 207-13.

17. Wells DW, Bernier WE. A single mesial canal and two distal canals in a mandibular second molar. J Endod 1984, 10: 400-3.

18. Manning SA. Root canal anatomy of mandibular second molars. Part II. C-shaped canals. Int Endod J 1990, 23: 40-5.

19. Rocha LF, Sousa Neto MD, Fidel SR, da Costa WF, Pecora JD. External and internal anatomy of mandibular molars. Braz Dent J 1996, 7: 33-40.

20. Demirbuga S, Sekerci AE, Dincer AN, Cayabatmaz M, Zorba YO. Use of cone-beam computed tomography to evaluate root and canal morphology of mandibular first and second molars in Turkish individuals. Med Oral Patol Oral Cir Bucal 2013, 18: e737-44.

\section{Yazışma Adresi}

Dr. Damla ÖZSU

Atatürk Üniversitesi

Diş Hekimliği Fakültesi

Endodonti Anabilim Dalı

ERZURUM

TIf: 04422360944-1746

Email: d_ozsu@hotmail.com 